\title{
Design of Colloidal Pt Catalysts Encapsulated by Silica Nano Membranes for Enhanced Stability in $\mathrm{H}_{2} \mathrm{~S}$ Streams
}

\author{
Vincenzo Roberto Calderone • Johanna Schütz-Widoniak • \\ G. Leendert Bezemer • Geert Bakker • Chantal Steurs • \\ Albert P. Philipse
}

Published online: 11 May 2010

(C) The Author(s) 2010. This article is published with open access at Springerlink.com

\begin{abstract}
Poisoning of platinum catalysts by sulphur compounds is a significant problem that prevents their application in untreated gas streams. We introduce a novel concept to circumvent the poisoning problem by encapsulating individual platinum nano-particles with silica layers that act as selective membranes. Greatly enhanced sulfur tolerance for sufficiently dense illustrates the potential of our approach to design noble metal catalysts that survive in sulphur containing gas streams.
\end{abstract}

Keywords Catalyst poisoning · Silica membranes . Platinum and silica colloids

Present Address:

V. R. Calderone

Van't Hoff Institute for Molecular Sciences, University of Amsterdam, Nieuwe Achtergracht 166, 1018 WV Amsterdam, The Netherlands

e-mail: v.r.calderone@uva.nl

G. L. Bezemer · G. Bakker · C. Steurs

Shell Technology Centre Amsterdam, Grasweg 31, 1031 HW

Amsterdam, The Netherlands

e-mail: Leendert.Bezemer@shell.com

G. Bakker

e-mail: Geert.Bakker@shell.com

C. Steurs

e-mail: Chantal.Steurs@shell.com

J. Schütz-Widoniak · A. P. Philipse ( $₫)$

Van't Hoff Laboratory for Physical and Colloid Chemistry,

Debye Institute, Utrecht University, Padualaan 8, $3584 \mathrm{CH}$

Utrecht, The Netherlands

e-mail: a.p.philipse@uu.nl

J. Schütz-Widoniak

e-mail: johanna.schuetz-widoniak@merck.de

\section{Introduction}

The synthesis of particles with well-defined properties is important for the development of new materials. Recently, much effort has been devoted to the controlled synthesis of various metal particles in the nano and micrometer size range [1,2]. Well-defined colloidal noble metal particles not only display chemical stability, but may also have high electrical conductivity and catalytic activity [3]. Their large surface area and high surface activity make these small particles excellent catalysts and photo catalysts for many organic reactions $[4,5]$.

Platinum colloids are frequently prepared by reduction of platinum compounds with IV and II valence with sodium borohydride [6]. Depending on synthesis techniques and on the kind of reactants, particles with various properties can be generated [7]. In the field of catalysis platinum nano-particles are widely applied for the hydrogenation of organic species [8,9]: at the laboratory scale for the enantioselective hydrogenation of fine chemicals $[10,11]$ and, at the production scale, for the hydrogenation of unsaturated hydrocarbons [12]. For catalysis at longer time scales a serious problem is poisoning of the catalyst, usually by sulphur compounds [13]. To enhance the life span of the catalyst the options are either to remove the sulphur based species from the reaction gas mixture [14] or to change the properties of the catalyst. Increasing the acidity of the support using zeolites, resulting in electron deficiency of the metal and consequently a lower metal surface interaction, as well as applying Pd-Pt alloys [15], has been reported to increase catalyst lifetime [16]. Moreover, the preparation of metal-based composite materials, via the self-assembly of inorganic-organic systems like reverse micelles, was found to be efficient to obtain catalysts with an enhanced resistance against 
aggregation and sintering [17-22]. The methods proved to be efficient in the Pt-silica systems as well [23].

Here we investigate a different approach namely to deposit a porous silica layer on the platinum surface with the idea to block the poison, or at least to substantially reduce its diffusion rate towards the catalyst, whereas ideally hydrogen diffuses much faster to the platinum surface. Hydrogen spill over to the silica outer layer will enable continuation of toluene hydrogenation in the sulphur containing gas stream. To achieve shape selectivity between $\mathrm{H}_{2}$ and $\mathrm{H}_{2} \mathrm{~S}$ is quite challenging, as their kinetic diameters are rather similar with 0.289 and $0.36 \mathrm{~nm}$, respectively. However, dense silica layers on membranes with typical pore sizes of $\sim 0.4 \mathrm{~nm}$ have been reported to have good selectivity between hydrogen and methane [24]. Since these molecules have a similar small size difference, selectivity between $\mathrm{H}_{2}$ and $\mathrm{H}_{2} \mathrm{~S}$ caused by a silica shell on Pt catalyst is a feasible option.

We propose two ways to deposit a silica layer on platinum colloids. The first strategy is to polymerize silica onto surface-modified platinum colloids. We investigate two types of surface modification, namely (i) platinum colloids stabilised with polyvinylpyrrolidone (PVP), a well known stabiliser for metal colloids that enhances the affinity for silica, and (ii) platinum colloids modified with various functionalised triethoxysilanes. The added functionality of the silane can be chosen to achieve good affinity for platinum. The ethoxy groups can be further hydrolysed together with growth of the silica layer via the Stöber method [25]. The second strategy to obtain silica-covered Pt particles is (i) start with silica spheres prepared via the Stöber synthesis, (ii) modify the silica with various functional triethoxysilanes to enhance the affinity for platinum, (iii) precipitate platinum colloids directly on the surface of silica particles, (iv) grow a silica layer on the metal particles employing hydrolysis of tetraethoxysilane (TEOS).

Densification of the resulting silica layers by a calcination treatment after immobilisation on a silica carrier is done at $500{ }^{\circ} \mathrm{C}$. Catalytic evaluation of the samples before and after deposition of the silica layer is performed by using the toluene hydrogenation as a model reaction, whereas sulphur resistance is measured for a gas stream containing 6 ppm $\mathrm{H}_{2} \mathrm{~S}$.

\section{Materials and Methods}

\subsection{Synthesis of Platinum Colloids}

Hexachloroplatinum hydride, $\mathrm{H}_{2} \mathrm{PtCl}_{6}(1 \mathrm{mg} / \mathrm{mL})$ in hydrochloride acid $(2 \mathrm{M})$ was found to be a suitable compound for the synthesis of the platinum particles in a redox reaction. Freshly double distilled water was used as solvent in all cases. When ethanol or mixtures of ethanol and water were tested as solvent, the redox reaction appeared to run slower: the particle formation took several days and did not lead to desirable results. As reductant $\mathrm{NaBH}_{4}$ solutions were used; two different concentrations were applied in this work: 0.1 and $0.2 \mathrm{M}$. The $\mathrm{NaBH}_{4}$ solutions were freshly prepared for every synthesis. To protect $\mathrm{Pt}$ particles against aggregation polyvinylpyrrolidone (PVP, 10000) solution $(0.3 \mathrm{~g} / \mathrm{L})$ was added. In a typical synthesis $1 \mathrm{~mL}$ of $\mathrm{Pt}$ precursor solution were mixed with $1 \mathrm{~mL}$ of PVP solution; $1 \mathrm{~mL}$ of $\mathrm{NaBH}_{4}$ solution was added all at once and the solution was not stirred during the reaction. All the syntheses took place at room temperature. Platinum dispersions were purified via several centrifugation steps (20000 rpm; Avanti J-20XP, Beckman Coulter) and washing with EtOH until neutrality of solution was achieved.

\subsection{Platinum-Silica Core-Shell Particles}

PVP stabilised platinum particles with a diameter of ca. $3 \mathrm{~nm}$ were used as substrate to prepare platinum-silica core-shell particles. To obtain the silica covering of the platinum colloids we made use of the Stöber method, with TEOS as silica precursor. The hydrolysis of TEOS took place in a suspension of platinum particles in a $\mathrm{H}_{2} \mathrm{O} / \mathrm{EtOH}$ solution at different $\mathrm{H}_{2} \mathrm{O} / \mathrm{EtOH}$ volume ratios in the range 2-40. Ammonia solution (29\%) was used to catalyse the hydrolysis reaction. The ratios between the water, ammonia and ethanol were varied in a wide range. No differences could be detected by adding TEOS slowly to the platinum suspension or all at once. The Pt particles coated with silica used for the catalytic test were prepared as follows: $10 \mathrm{~mL}$ of $0.2 \mathrm{mg} / \mathrm{mL}$ platinum suspension was mixed with $3 \mathrm{~mL}$ of $29 \%$ ammonia solution, then $60 \mu \mathrm{L}$ of $10 \%$ ethanol TEOS solution: was added. Platinum-silica core-shell particles were purified by washing with $\mathrm{EtOH}$ and centrifugation until neutrality of the suspension was reached.

\subsection{Platinum Decorated Silica Particles}

Carrier silica particles with a diameter of about $350 \mathrm{~nm}$ were synthesised in a mixture of $1750 \mathrm{~mL}$ freshly distilled ethanol and $176 \mathrm{~mL}$ of ammonia solution (28.6\%) to which $75 \mathrm{~mL}$ distilled TEOS was added via a funnel under the fluid surface. The surface of the particles was modified by hydrolysis of aminopropyltriethoxysilane (APTES), mercaptopropyltri-ethoxysilane (MPTES) or diphenylphosphinoethyltriethoxysilane (DPTES) as follows. $100 \mathrm{~mL}$ of the carrier silica dispersion $(14 \mathrm{mg} / \mathrm{mL}), 200 \mathrm{~mL}$ of ethanol, $1 \mathrm{~mL}$ of ammonia solution $(28.6 \%)$ and $1 \mathrm{~mL}$ of MPTES and APTES, respectively, were found to give good results; in the case of DPTES $1.5 \mathrm{~mL}$ of the linker was 
added. Once the suspension of surface-modified silica was purified by multiple centrifugations, the silica particles were dispersed in water in which reduction of $\mathrm{H}_{2} \mathrm{PtCl}_{6}$ took place by means of $\mathrm{NaBH}_{4} .50 \mathrm{~mL}$ of coated silica dispersion in distilled water $(3 \mathrm{mg} / \mathrm{mL}), 2 \mathrm{~mL}$ of hexachloroplatinum hydride $(1 \mathrm{mg} / \mathrm{mL})$ in hydrochloride acid (2 M) and $2 \mathrm{~mL}$ of $0.01 \mathrm{M}$ sodium borohydride solution was found to be the optimum composition for the one-pot synthesis of platinum particles on silica spheres.

To deposit a thin layer $(5-10 \mathrm{~nm})$ of silica on the platinum decorated silica particles, the purified platinum decorated silica particles $(0.65 \mathrm{~g})$ were dispersed in $208 \mathrm{~mL}$ of EtOH and $98 \mathrm{~mL}$ of $\mathrm{NH}_{4} \mathrm{OH}$, next adding $1.09 \mathrm{~mL}$ of TEOS. The outer silica layer can be densified in a further hydrolysis step in an acidic environment. $5 \mu \mathrm{L}$ of TEOS was added to a suspension of silica decorated particles $(1 \mathrm{~g} / 100 \mathrm{~mL})$ in ethanol containing $1 \%$ of concentrated $\mathrm{HCl}$ solution (37\%). The particles were then recovered after $24 \mathrm{~h}$ by centrifugation.

\subsection{Particle Characterisation}

The size and morphology of the particles were characterised by TEM imaging (Figs. 1, 2, 3, 4, 5, 6, 7 and 8). A drop of suspension was deposited on a polymer coated copper grid. The samples were analysed by means of a Tecnai $10(100 \mathrm{kV})$. The mean size of the particles was calculated on the basis of the measurement of at least 300 particle sizes via Analysis Image Processing program.

\subsection{Immobilization of Colloids on Silica}

Colloidal suspensions containing $10 \mathrm{mg}$ PVP stabilised platinum colloids were added to an aqueous suspension containing $2 \mathrm{~g}$ of a wide pore silica support and stirred for $18 \mathrm{~h}$. After centrifugation, the silica powders were dried over night at $50{ }^{\circ} \mathrm{C}$, followed by a $2 \mathrm{~h}$ drying step at
$120{ }^{\circ} \mathrm{C}$ to be finally calcined at $500{ }^{\circ} \mathrm{C}$ for $2 \mathrm{~h}$. The resulting powders were pressed at 2000 bars, crushed and sieved for the toluene hydrogenation test.

\subsection{Toluene Hydrogenation Testing}

Catalytic performances were evaluated for hydrogenation of toluene to methylcyclohexane $(\mathrm{MCH})$ in a plug flow reactor at atmospheric pressure after a reduction treatment at $400{ }^{\circ} \mathrm{C}$ for $1 \mathrm{~h}$ in pure hydrogen. After cooling to $50{ }^{\circ} \mathrm{C}$ the hydrogen was saturated with toluene at $16^{\circ} \mathrm{C}$ leading to a $1.8 \mathrm{v} / \mathrm{v} \%$ concentration of toluene in hydrogen and fed to the reactor. Activity and selectivity of the catalysts were measured with quantitative mass spectrometry (MS) in the temperature window from 50 to $325{ }^{\circ} \mathrm{C}$ after a stabilisation period of $10 \mathrm{~min}$ at each temperature. In order to calculate the apparent activation energies Ln $\mathrm{k}$ was plotted versus $1 / \mathrm{T}$ in the conversion range of $2-40 \%$. From this data the $\mathrm{E}_{\mathrm{a}}$ was calculated from the slope of the linear part of the graph.

The sulphur resistance of the catalysts was measured in a separate experiment in the same plug flow reactor at $100{ }^{\circ} \mathrm{C}$ using $50 \mathrm{mg}$ of catalyst. Once stable conversions were obtained, $\mathrm{H}_{2} \mathrm{~S}$ in $\mathrm{Ar}$ was added to the feed resulting in a concentration of $6 \mathrm{ppm}$ in the total flow of $25 \mathrm{~mL} / \mathrm{min}$. Again MS was used to follow $\mathrm{MCH}, \mathrm{H}_{2} \mathrm{~S}$ and $\mathrm{Ar}$ evolution in time. The time between detection of Ar and total disappearance of $\mathrm{MCH}$ is defined as time till complete deactivation.

\section{Results and Discussion}

\subsection{Platinum Colloids}

Many methods have been reported for the synthesis of platinum colloids, most of which employ the reduction of
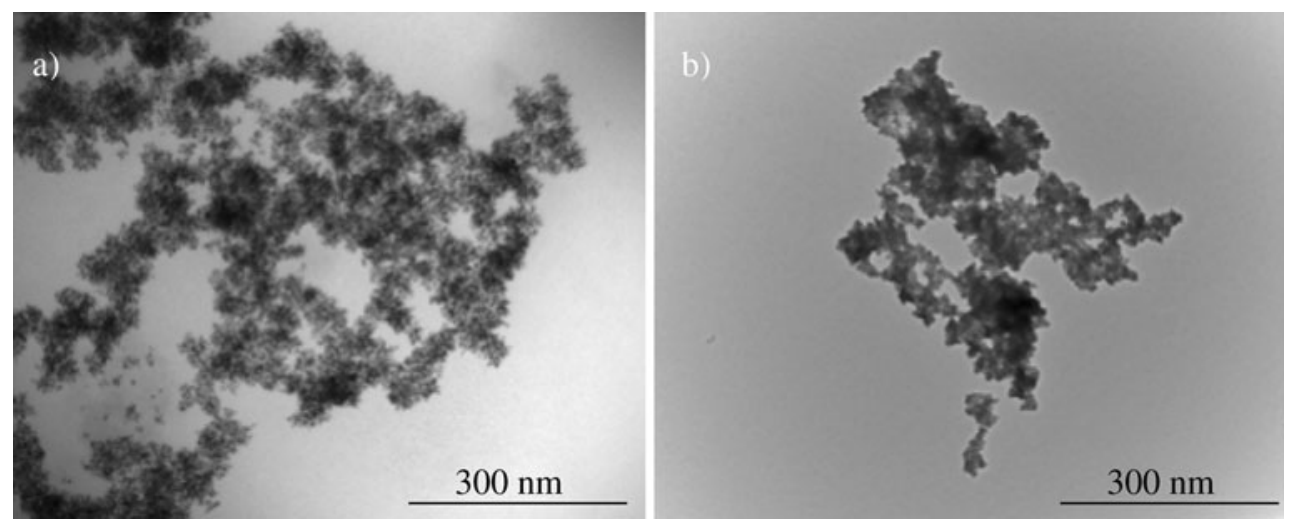

Fig. 1 TEM image of platinum particles formed with DPTES as stabilising agent. a $[\mathrm{Pt}]=7 \times 10^{-5},[\mathrm{DPTES}] /[\mathrm{Pt}]=1,\left[\mathrm{NaBH}{ }_{4}\right] /[\mathrm{Pt}]=200$. b $[\mathrm{Pt}]=7 \times 10^{-5},[\mathrm{DPTES}] /[\mathrm{Pt}]=10,\left[\mathrm{NaBH}_{4}\right] /[\mathrm{Pt}]=200$. The aggregation increases by increasing the $[\mathrm{DPTES}] /[\mathrm{Pt}] \mathrm{ratio}$ 


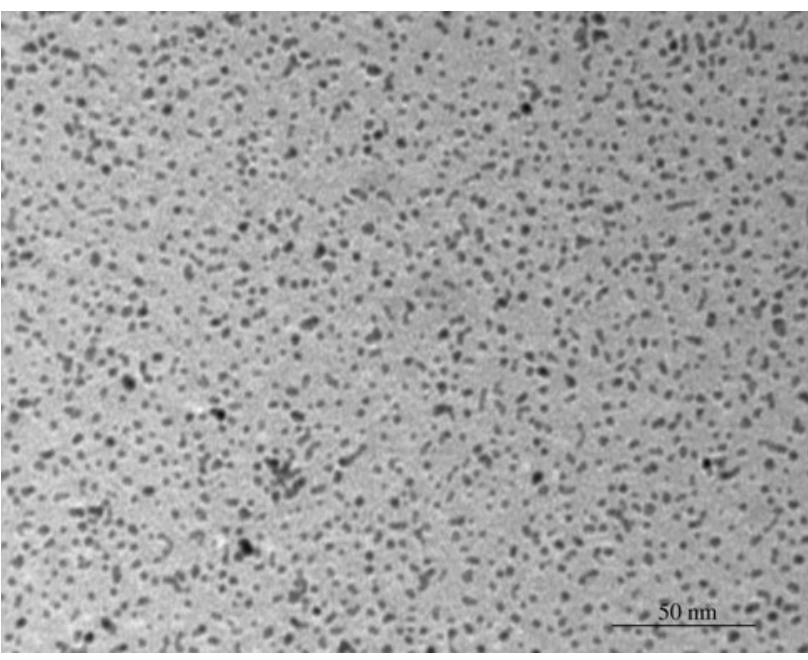

Fig. 2 TEM image of platinum particles synthesised in the following conditions: $[\mathrm{Pt}]=1.60 \times 10^{-3},\left[\mathrm{NaBH}_{4}\right] /[\mathrm{Pt}]=7.8,[\mathrm{PVP}] /[\mathrm{Pt}]=$ 0.07 . Stable platinum colloids are formed with an average radius of $2.8 \pm 0.7 \mathrm{~nm}$

Pt II, Pt IV compounds, organic as well as inorganic. It is also possible to prepare platinum colloids in reverse micelles systems; drawbacks are a low yield and the difficult purification of the platinum sols. In this work we perform the reduction of $\mathrm{H}_{2} \mathrm{PtCl}_{6}$ by $\mathrm{NaBH}_{4}$ in aqueous media; addition of ethanol slows down the redox reaction and particle formation too much (several days). Platinum particles easily aggregate in water so it is necessary to perform their synthesis in presence of a suitable stabilising agent. In anticipation of the covering with silica we investigated two stabilising agents: DPTES and PVP. The ability of the phosphine moiety of DPTES to bind to noble metals is well documented [26, 27]. The use of DPTES modifies the surface of the particles such that silanol groups are exposed. This indeed allows to deposit a silica shell onto the platinum particles via hydrolysis of TEOS. Also PVP is a well-known stabilising agent for metal particles that also enhances the affinity of silica for the metal surface [28-30]. The reaction has been conducted at different concentrations of $\mathrm{Pt}$ and with different $\mathrm{Pt} / \mathrm{NaBH}_{4}$ and Pt/DPTES ratios. The synthesis at low DPTES concentration leads to aggregated particles. Aggregated particles were also obtained by increasing the DPTES/Pt ratio (Fig. 1). This is probably due to the fact that the reduction reaction and the hydrolysis of DPTES occurs simultaneously; the hydrolysis and condensation reaction lead to the interconnection of DPTES molecules and of the bonded platinum particles. Using PVP as stabiliser it turns out to be possible to synthesise stable, discrete Pt colloids with a diameter below $5 \mathrm{~nm}$. The average particle size is a weak function of Pt/PVP ratio and generally falls in the 2-4 nm range. The optimum amounts of reactants were found to be $2 \mathrm{~mL}$ of hexachloroplatinum hydride $(1 \mathrm{mg} / \mathrm{mL})$ in
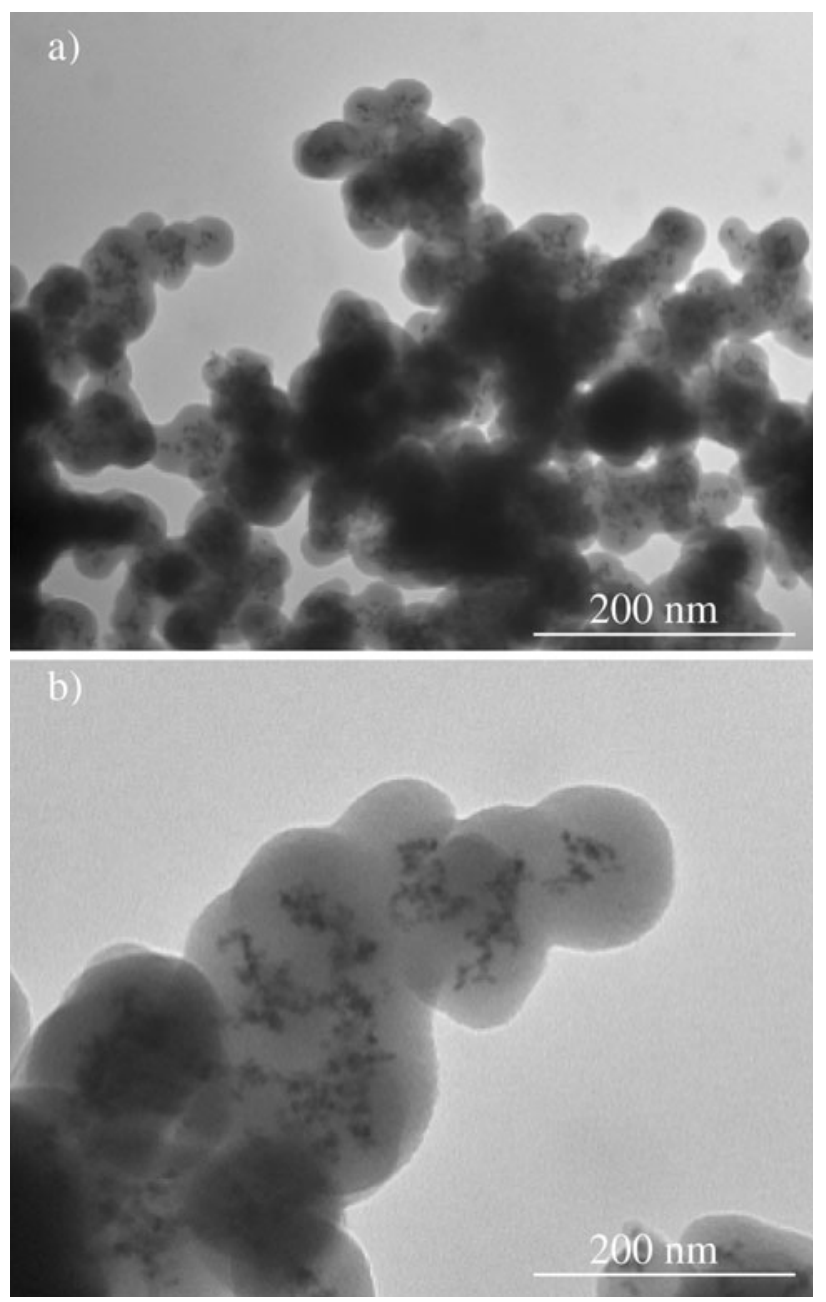

Fig. 3 TEM images of platinum silica core/shell particles. a-b $0.2 \mathrm{mg} / \mathrm{mL}$ platinum suspension: $10 \mathrm{~mL}, 29 \%$ ammonia solution: $3 \mathrm{~mL}, 10 \%$ TEOS solution: $60 \mu \mathrm{L}$. Effect of high ionic strength on the coating process

hydrochloride acid (2 M) and $4 \mathrm{~mL}$ of $0.02 \mathrm{M}$ of sodium borohydride. $2.0 \mathrm{~mL}$ PVP solution in water $(0.3 \mathrm{~g} / 100 \mathrm{~mL})$ was added to the solvent before addition of the reductant to stabilise the platinum particles and to prevent the aggregation. PVP (MW 10000) was found to be the best suitable stabilising agent for this synthesis. The use of PVP polymers with higher molecular weights lead to a much longer formation time of the platinum particles. The PVP stabilised platinum particles $(2.8 \pm 0.7 \mathrm{~nm})$ used for coating with silica are shown in Fig. 2.

\subsection{Platinum-Silica Colloids}

The covering of platinum colloids via hydrolysis of TEOS in a suspension of platinum particles in an ethanolammonia mixture works well. The synthesis conditions, however, must be tailored very carefully: in particular the ionic strength (i.e. the ammonia concentration) must be 


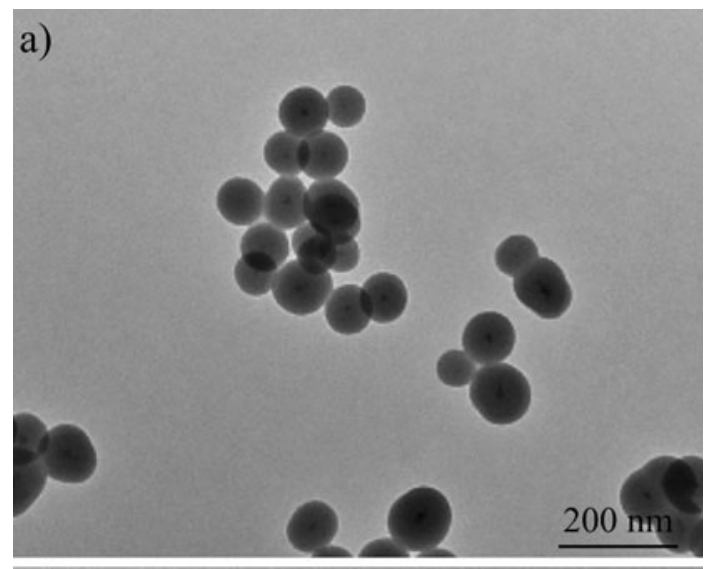

b)

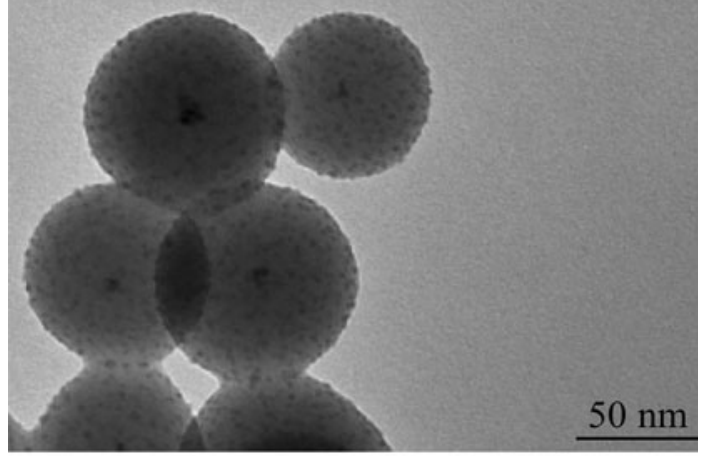

c)

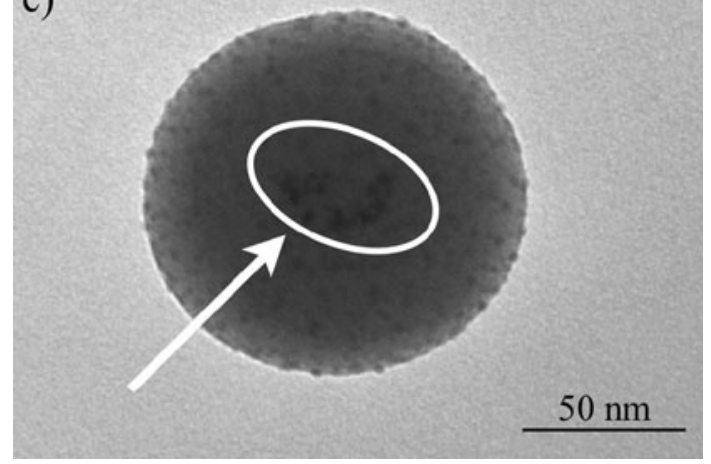

Fig. 4 TEM images of platinum silica core/shell particles. a-b $0.2 \mathrm{mg} / \mathrm{mL}$ platinum suspension: $10 \mathrm{~mL}, 29 \%$ ammonia solution: $1.5 \mathrm{~mL}, 10 \%$ TEOS solution: $10 \mu \mathrm{L} \times 6$ times. Silica shell surrounds many platinum particles. c The white arrow indicates the actual $\mathrm{Pt}$ colloids. The heating, due to the electron beam, is responsible for the slightly lighter features (silica protrusions) on the overall particles due to the evolution of residual ethoxy groups present in the silica

adjusted such that it is sufficient to lower the electrostatic barrier between the platinum particles and the forming silica nuclei (allowing them to deposit on the surface of platinum particles), but not too high otherwise the platinum particles aggregate. Figure 3 shows the typical result when the ionic strength of the suspension is too high and the hydrolysis process too fast. The Pt colloids aggregated during the fast hydrolysis and they were entrapped in the

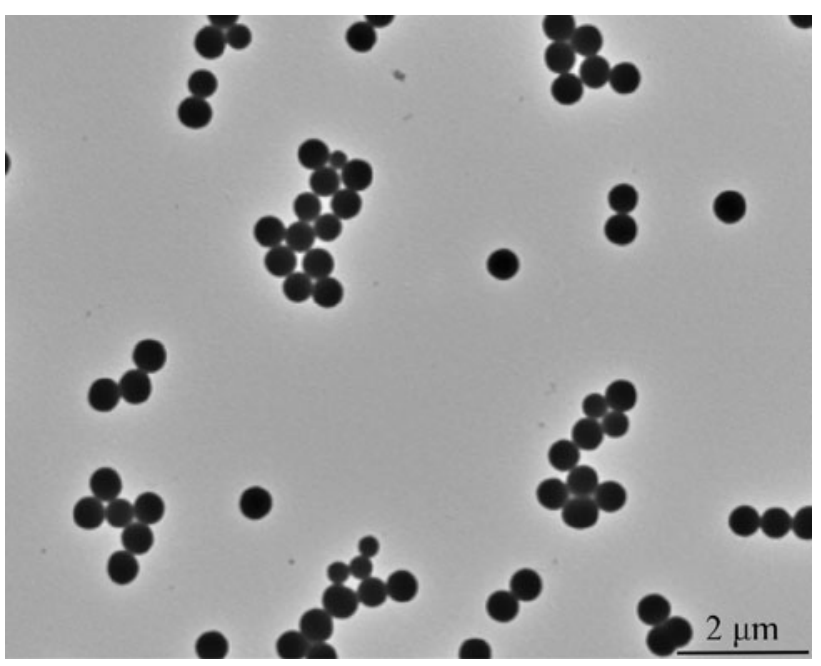

Fig. 5 TEM image of carrier silica particles. $117 \mathrm{~mL}$ EtOH, $11.7 \mathrm{~mL}$ $\mathrm{NH}_{4} \mathrm{OH}, 5 \mathrm{~mL}$ TEOS

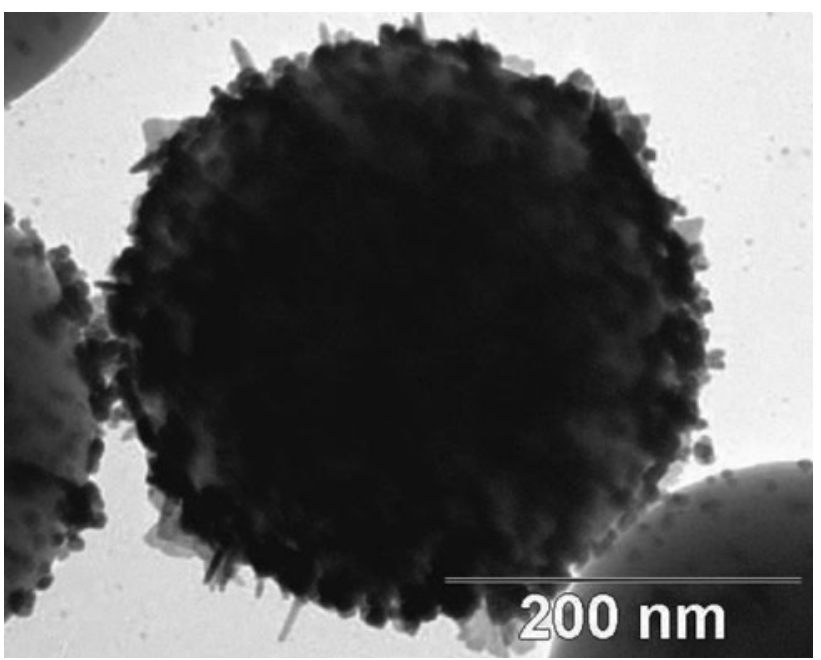

Fig. 6 TEM image of platinum $(10 / 650 \mathrm{mg})$ decorated silica particles. $50 \mathrm{~mL}$ of coated silica dispersion in distilled water $(3 \mathrm{mg} / \mathrm{mL})$, $2 \mathrm{~mL}$ of $\mathrm{H}_{2} \mathrm{PtCl}_{6}(1 \mathrm{mg} / \mathrm{mL})$ in hydrochloride acid $(2 \mathrm{M}), 2 \mathrm{~mL}$ of $0.01 \mathrm{M} \mathrm{NaBH}_{4}$

silica matrix. Better results were obtained by adding TEOS slowly. Via this method we obtain core-shell colloids with a $30 \mathrm{~nm}$ silica shell and 5-10 platinum particles as a core (Fig. 4). With both the methods we obtained core-shell particles with several platinum particles in the core. Only the latter sample was further characterized from the catalysis point of view.

\subsection{Platinum Decorated Silica Carriers}

To fix noble metal particles onto silica carriers (Fig. 5), the carriers were coated with various linkers containing heteroatoms with high affinity and for platinum. The concentrations of the silica spheres, coating agent, ammonia solution 


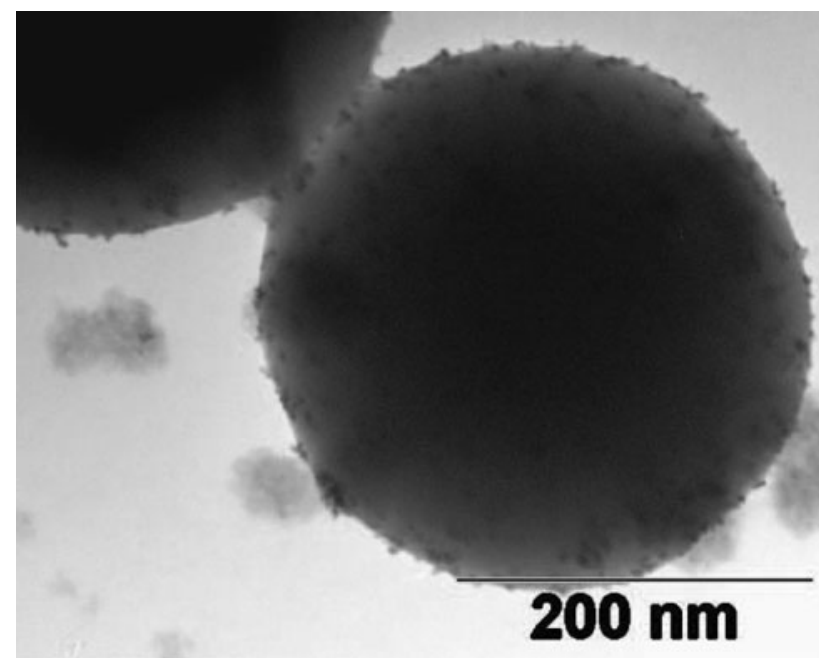

Fig. 7 TEM image of platinum $(10 / 650 \mathrm{mg})$ decorated silica particles. $50 \mathrm{~mL}$ of coated silica dispersion in distilled water $(3 \mathrm{mg} / \mathrm{mL})$, $2 \mathrm{~mL}$ of $\mathrm{H}_{2} \mathrm{PtCl}_{6}(1 \mathrm{mg} / \mathrm{mL})$ in hydrochloride acid $(2 \mathrm{M}), 2 \mathrm{~mL}$ of $0.01 \mathrm{M} \mathrm{NaBH}_{4}, 2.0 \mathrm{~mL}$ PVP solution in water $(0.3 \mathrm{~g} / 100 \mathrm{~mL})$

and ethanol were varied to obtain optimum results. APTES and DPTES were used as coating reactants. Once the suspension of coated silica was purified by multiple centrifugations, the silica was dispersed in water in which reduction of $\mathrm{H}_{2} \mathrm{PtCl}_{6}$ took place using of $\mathrm{NaBH}_{4}$. Despite reports on the irreversible adsorption of single platinum particles on inorganic fibers [31], we observed here that the reduction reaction without any stabilising agent leads to the formation of aggregated particles on the surface of the silica particles (Fig. 6). To deposit non-aggregated platinum particles it is necessary to make use of PVP, $2.0 \mathrm{~mL}$ PVP solution in water $(0.3 \mathrm{~g} / 100 \mathrm{~mL})$. In this way we can decorate silica particles $($ diameter $=350 \mathrm{~nm})$ with platinum particles less than $5 \mathrm{~nm}$ in size. The use of DPTES, the linker containing a phosphorous atom with a strong affinity to platinum, is the most effective to fix platinum particles on the modified silica surface (Fig. 7). Next we succeeded in depositing a thin layer $(5-10 \mathrm{~nm})$ of silica on the platinum decorated silica particles. The purified platinum decorated silica particles $(0.65 \mathrm{~g})$ were dispersed in $208 \mathrm{~mL}$ of $\mathrm{EtOH}$ and $98 \mathrm{~mL}$ of $\mathrm{NH}_{4} \mathrm{OH}$, then $1.09 \mathrm{~mL}$ of TEOS was added (Fig. 8), and in a further step we densified the outer silica layer (Fig. 9) as described in Sect. 2.3. A summary of the major characteristics of the samples which catalytic activity was tested is reported in Table 1 .

\subsection{Catalysis Tests}

\subsubsection{Toluene Hydrogenation}

In Fig. 10 the $\mathrm{MCH}$ formation as a function of temperature is shown for the different samples under study. The activity of the uncoated platinum colloids was very high and
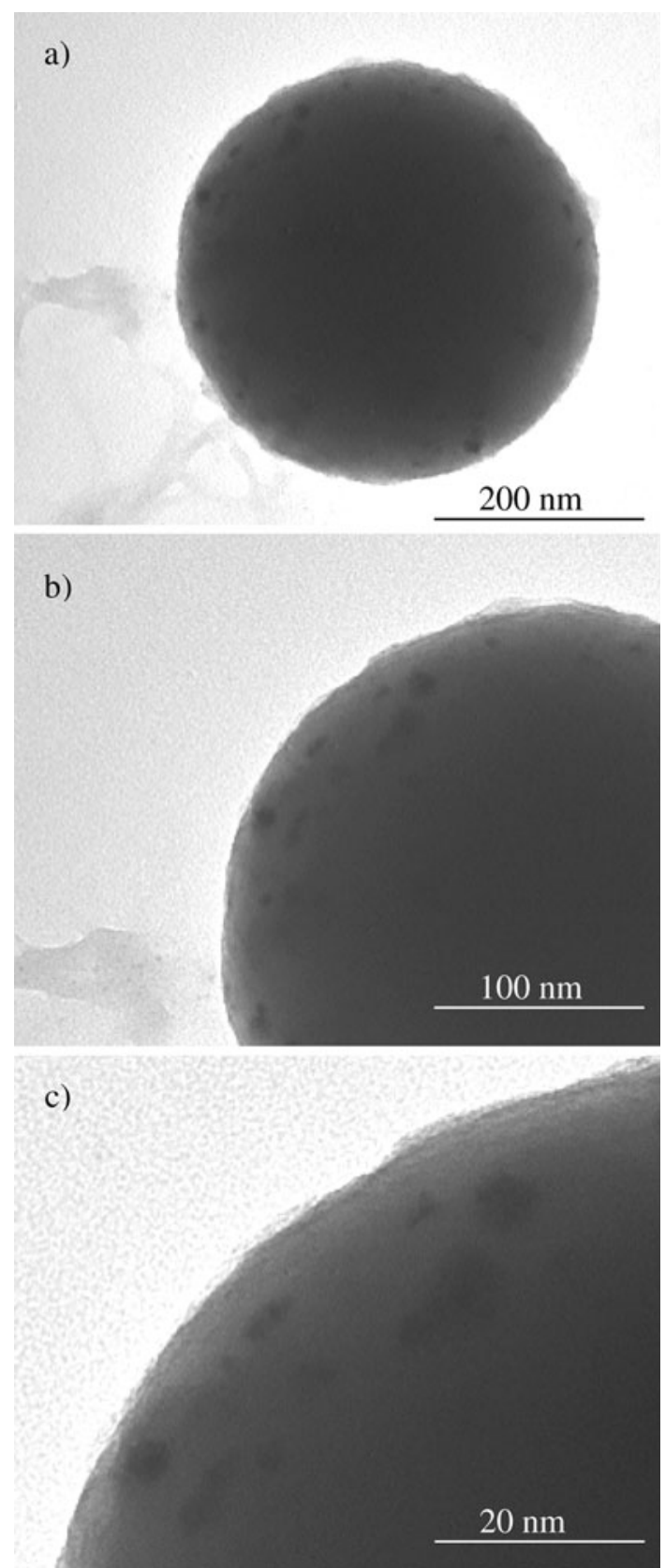

Fig. 8 TEM image of platinum decorated silica particles covered with $10 \mathrm{~nm}$ silica layer. a-c $(0.65 \mathrm{~g})$ of platinum decorated silica particles were dispersed in $208 \mathrm{~mL}$ of EtOH and $98 \mathrm{~mL}$ of $\mathrm{NH}_{4} \mathrm{OH}$, then $1.09 \mathrm{~mL}$ of TEOS was added

reached complete conversion at $120{ }^{\circ} \mathrm{C}$. The activity of the silica-coated colloids was lower and reached highest conversion of $28 \%$ at $150{ }^{\circ} \mathrm{C}$. Apparently in the process of coating active platinum sites became blocked by silica or were otherwise lost for the reaction. From Fig. 4 sintering of Pt colloids seems to have taken place, which would explain the lower activity as well. Pt colloids directly immobilized on silica performed slightly better with $32 \%$ conversion at $150{ }^{\circ} \mathrm{C}$, a value that dropped to only $16 \%$ 


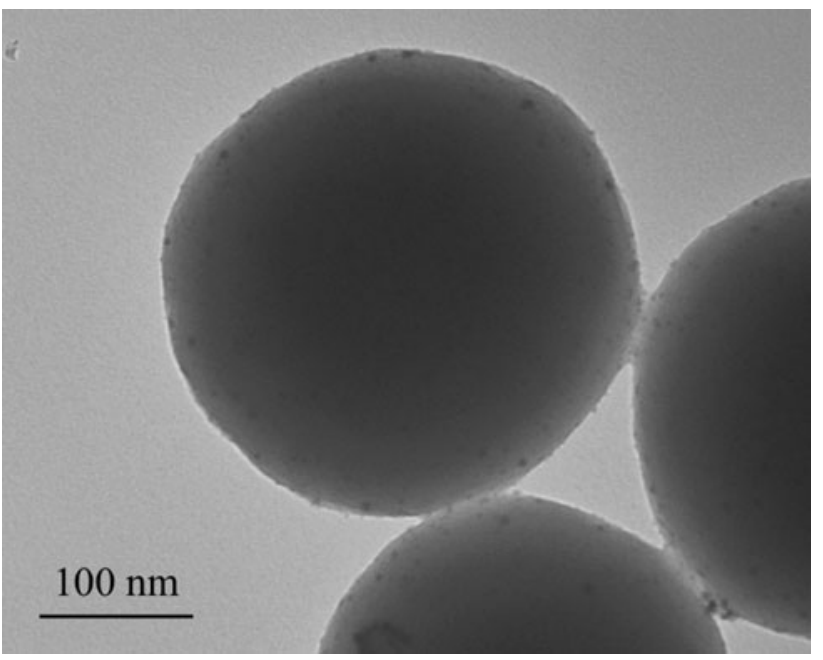

Fig. 9 TEM image of densified platinum decorated silica particles covered with $5 \mathrm{~nm}$ silica layer. $5 \mu \mathrm{L}$ of TEOS was added to a suspension of silica decorated particles $(1 \mathrm{~g} / 100 \mathrm{~mL})$ in ethanol containing $1 \%$ of concentrated $\mathrm{HCl}$ solution $(37 \%)$

after decoration with silica, once again showing the effect of the coating step on activity, although less pronounced. It has be noted that for this catalysts system no Pt sintering was apparent. After densification of the silica layer an activity of $60 \%$ at $150{ }^{\circ} \mathrm{C}$ was obtained, suggesting no negative effect of the coating step for this sample. However, the Pt loading of this catalyst was $1.25 \mathrm{wt} \%$, 2.5 times higher than for the other catalysts under study. If this activity difference is taken into account it once again appears that coating with silica has reduced the activity for the toluene hydrogenation at both 100 and $150{ }^{\circ} \mathrm{C}$.
Subsequently we calculated the apparent activation energies of the catalysts in order to relate the silica effect to possibly changes in catalytic regime by eg. hydrogen spillover catalysis.

The $E_{a}$ of the samples under study is listed together with conversions at 100 and $150{ }^{\circ} \mathrm{C}$ in Table 2 below. Only small differences in activation energy were obtained for the uncoated samples compared to the coated, but not densified samples $(43-47 \mathrm{~kJ} / \mathrm{mol})$. This indicates that the same type of catalysis is taking place for these catalysts and that the active platinum surface is accessible for both toluene and hydrogen. In the introduction we mentioned that hydrogenation reactions on a platinum colloid covered with a dense silica layer might still be possible if hydrogen spill takes place. In that instance we would expect a change in the rate-limiting step and a different apparent activation energy. This is definitely not the case for these catalyst and apparently the silica layer is not dense enough and toluene and hydrogen are still able to reach the metal surface. In order to proof this further a catalyst was prepared in which the silica layer was densified according to the procedure described at the end of Sect. 2.3. For this catalyst a higher activation energy of $60 \mathrm{~kJ} / \mathrm{mol}$ was obtained, suggesting a change in the rate-limiting step and potentially higher tolerance for $\mathrm{H}_{2} \mathrm{~S}$.

\subsubsection{Sulphur Tolerance}

Each catalyst was loaded again and after activation subjected to a toluene hydrogen stream at $100{ }^{\circ} \mathrm{C}$. Once stable conversion was reached, the $6 \mathrm{ppm} \mathrm{H}_{2} \mathrm{~S}$ in $\mathrm{Ar}$ was added

Table 1 Summary of the samples details reported in this work

\begin{tabular}{llll}
\hline Sample & TEM & Silica thickness (nm) & Catalytic test \\
\hline Uncoated $\mathrm{Pt}$ & Fig. 2 & - & Yes \\
$\mathrm{Si}$ coated $\mathrm{Pt} 1$ & Fig. 3 & 30 & Yes \\
$\mathrm{Si}$ coated $\mathrm{Pt} 2$ & Fig. 4 & $20-50$ & No \\
Uncoated $\mathrm{Pt}$ decorated on $\mathrm{SiO}_{2}$ & Fig. 7 & - & Yes \\
$\mathrm{SiO}_{2}$ coated $\mathrm{Pt}$ decorated on $\mathrm{SiO}_{2}$ & Fig. 8 & 5 & Yes \\
Densified $\mathrm{SiO}_{2}$ coated $\mathrm{Pt}$ decorated on $\mathrm{SiO}_{2}$ & & 5 & Yes \\
\hline
\end{tabular}

Table 2 Activity level at 100 and $150{ }^{\circ} \mathrm{C}$, together with apparent activation energy calculated from the data

\begin{tabular}{llccc}
\hline & $\begin{array}{l}\text { Conversion at } \\
100{ }^{\circ} \mathrm{C}(\%)\end{array}$ & $\begin{array}{l}\text { Conversion at } \\
150{ }^{\circ} \mathrm{C}(\%)\end{array}$ & $\begin{array}{l}\text { Apparent activation } \\
\text { energy (kJ/mol) }\end{array}$ & $\begin{array}{l}\text { Time till complete } \\
\text { deactivation }(\text { min) }\end{array}$ \\
\hline Uncoated $\mathrm{Pt}$ & 58 & 100 & 47 & 9 \\
$\mathrm{Si}$ coated $\mathrm{Pt}$ & 7 & 28 & 43 & 6 \\
Uncoated $\mathrm{Pt}$ decorated on $\mathrm{SiO}_{2}$ & 7 & 32 & 43 & 9 \\
$\mathrm{SiO}_{2}$ coated $\mathrm{Pt}$ decorated on $\mathrm{SiO}_{2}$ & 5 & 16 & 47 & 5 \\
Densified $\mathrm{SiO}_{2}$ coated $\mathrm{Pt}$ decorated on $\mathrm{SiO}_{2}$ & 7 & 59 & 60 & 502 \\
\hline
\end{tabular}




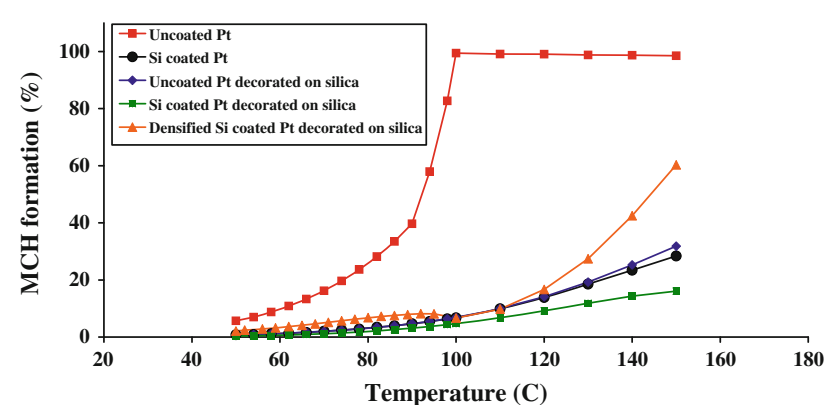

Fig. 10 Toluene to methylcyclohexane conversion versus temperature for uncoated and silica decorated platinum colloids

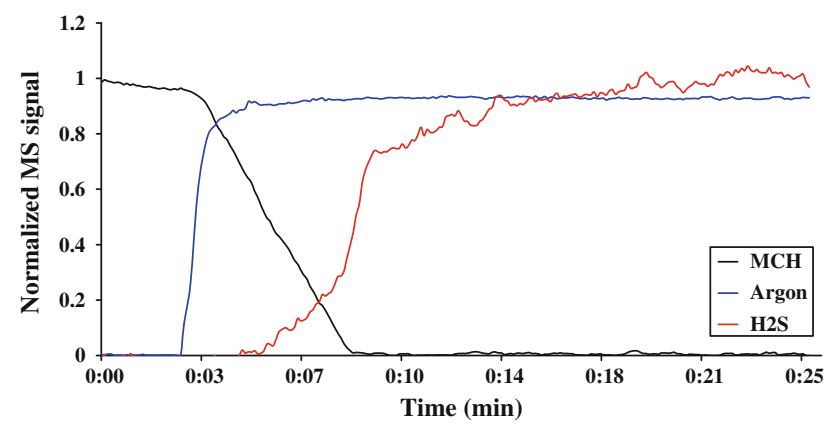

Fig. 11 Methylcyclohexane formation in time after $\mathrm{H}_{2} \mathrm{~S}$ in $\mathrm{Ar}$ was added to the feed for silica coated Pt colloids

to the feed. Figure 11 shows for the silica-coated colloids the evolution in time of mass 34,40 and 98, that correspond to $\mathrm{H}_{2} \mathrm{~S}$, Ar and $\mathrm{MCH}$, respectively. Directly with detection of $\mathrm{Ar}$ a decline in the MCH level is apparent. 3 min later $\mathrm{H}_{2} \mathrm{~S}$ appears; at that moment the conversion to $\mathrm{MCH}$ has dropped already by $50 \%$. About 3 min later no $\mathrm{MCH}$ is detected anymore, whereas $\mathrm{H}_{2} \mathrm{~S}$ levels are still increasing. Similar deactivation patterns are found for all samples under study; time between Ar break-through and complete deactivation is reported in Table 2. Now it is clear that all catalysts except the densified sample deactivated quickly without any measurable beneficial effect of the silica layer. To the contrary, the silica-coated samples deactivated even faster compared to the uncoated samples. However, for a fair comparison the initial activity of the catalysts has to be taken into account. Comparing the conversions at $100{ }^{\circ} \mathrm{C}$ it is clear that $\mathrm{Si}$ coated $\mathrm{Pt}$ sample had a eight times lower activity compared to Uncoated Pt to start with. Time till complete deactivation was 8 and $6 \mathrm{~min}$, respectively, indicating slightly delayed deactivation by sulphur for the silica-coated sample. For the Pt decorated on silica samples the difference in stability against deactivation is in the same order as the initial activity difference, showing no positive effect of silica coating. The reason for the different behaviour of silica-coated samples is probably related to the differences in the silica layer thickness.

As retardation of poisoning by silica was at most modest for the examples discussed so far, we can thus infer that silica layers in this study generally are not dense enough to prevent poisoning: $\mathrm{H}_{2} \mathrm{~S}$ can thus diffuse into the pores and reaches the platinum surface.

Further proof for this hypothesis comes from the coated sample with a densified silica layer. Here an increase in sulphur tolerance of 100 times compared to the not densified samples was found. After correcting for higher $\mathrm{Pt}$ loading a 40 times better sulphur resistance remains. This shows that the idea of nano membranes of silica surrounding individual platinum particles can only work if proper densification of the silica layer is provided. However, even after the densification step, still deactivation took place. For this two possible explanations can be given. Firstly, it is possible that the majority of the pores are in the $\sim 0.4 \mathrm{~nm}$ region as found for dense silica membranes, but that some bigger pores are still present through which $\mathrm{H}_{2} \mathrm{~S}$ can diffuse, be it at slower pace. Alternatively one could argue that even if all pores are in the desired small range a much better shape selectivity of $\mathrm{H}_{2}$ and $\mathrm{H}_{2} \mathrm{~S}$ than needed for membrane applications would be necessary to prevent deactivation. As a first approximation the increased sulphur tolerance can be compared to a perm selectivity of 40 , which is impressive given the membrane layer thickness of only $5-10 \mathrm{~nm}$. For future work the focus should be on the development of thicker and still more dense silica layers to further enhance of shape selectivity between $\mathrm{H}_{2}$ and $\mathrm{H}_{2} \mathrm{~S}$. Present results show that toluene hydrogenation can take place on a silica-covered surface and that large improvements in sulphur tolerance are possible using deposition of very thin silica layers on individual platinum particles.

\section{Conclusions}

Various platinum-silica composite colloids were synthesized and tested as catalysts for the hydrogenation of aromatics compounds. PVP stabilised platinum particles can be obtained by the reduction of $\mathrm{H}_{2} \mathrm{PtCl}_{6}$ with $\mathrm{NaBH}_{4}$ aqueous solutions, with controlled particle diameter in the range of $2-4 \mathrm{~nm}$, and a size polydispersity below $25 \%$. Platinum-silica core-shell particles with more than one platinum colloid in the core can be obtained; the shell thickness can be adjusted for values of about $20 \mathrm{~nm}$ and larger. Silica particles (radius $350 \mathrm{~nm}$ ) can be decorated with platinum colloids with size below $5 \mathrm{~nm}$, where the silica is modified with DPTES or APTES to increase the affinity between silica and platinum particles. DPTES was found to be most effective to fix the platinum particles on the modified silica surface. The Pt IV reduction process 
should take place in presence of PVP to avoid the exaggerate growth of the particles up to ca. $50 \mathrm{~nm}$. Platinum colloids were successfully immobilised on a silica carrier and showed activity in the toluene hydrogenation reaction. Uncoated platinum colloids showed the highest activity and due to the coating a significant amount of activity was lost, partly due to sintering of Pt. Catalysts with an undensified silica layer showed only modest resistance to sulphur poisoning, indicating that the silica layer was either incomplete or not dense enough. A densification of the silica layer resulted in an increase in the apparent activation energy as the rate-limiting step now changes in the hydrogen spill over regime. Sulphur tolerance was greatly enhanced for the catalyst with the densified silica layer, showing the potential of the current strategy to design noble metal catalysts that can survive in sulphur streams.

Acknowledgments We kindly thank Dr. Anne-Sophie Millerioux and Dr. Marije Nijkamp for immobilisation of the Pt colloids on silica and doing initial experiments. We thank Dr. Herman Kuipers and Dr. Donald Reinalda for their interest in this work and SenterNovem (Dutch Ministry of Economic Affairs) for financial support.

Open Access This article is distributed under the terms of the Creative Commons Attribution Noncommercial License which permits any noncommercial use, distribution, and reproduction in any medium, provided the original author(s) and source are credited.

\section{References}

1. Bezemer GL, Bitter JH, Kuipers HPCE, Oosterbeek H, Holewijn JE, Xu XD, Kapteijn F, van Dillen AJ, de Jong KP (2006) J Am Chem Soc 128:3956

2. Cushing BL, Kolesnichenko VL, O'Connor CJ (2004) Chem Rev 104:3893

3. Burda C, Chen X, Narayanan R, El-Sayed MA (2005) Chem Rev 105:1025
4. Roucoux A, Schulz J, Patin H (2002) Chem Rev 102:3757

5. Johnson BFG (2003) Top Catal 24:147

6. Duff DG, Edwards PP, Johnson BFG (1995) J Phys Chem 99:15934

7. Yu YT, Zhang QH, Xu BQ (2004) Prog Chem 16:520

8. Chen CW, Serizawa T, Akashi M (1999) Chem Mater 11:1381

9. Mei Y, Sharma G, Lu Y, Ballauff M, Drechsler M, Irrgang T, Kempe R (2005) Langmuir 21:12229

10. Baiker A (1997) J Mol Catal A Chem 115:473

11. Baddeley CJ (2003) Top Catal 25:17

12. Fujikawa T, Idei K, Ebihara T, Mizuguchi H, Usui K (2000) Appl Catal A Gen 192:253

13. Bartholomew CH, Agrawal PK, Katzer JR (1982) Adv Catal $31: 135$

14. Song C, Ma XL (2003) Appl Catal B Environ 41:207

15. Navarro RM, Pawelec B, Trejo JM, Mariscal R, Fierro JLG (2000) J Catal 189:184

16. Song C (1999) Am Chem Soc Symposium Series 738:381

17. Kong TSA, Yu KMK, Tsang SC (2006) J Nanosci Nanotechnol 6:1167

18. Yu KMK, Yeung CMY, Thompsett D, Tsang SC (2003) J Phys Chem B 107:4515

19. Yu KMK, Thompsett D, Tsang SC (2003) Chem Commun 13:1522

20. Yu K, Wu Z, Zhao Q, Li B, Xie Y (2008) J Phys Chem C 112:2244

21. Lee J, Park J, Song H (2008) Adv Mater 20:1523

22. Arnal P, Comotti M, Schüth F (2006) Angew Chem Int Ed 45:8224

23. Joo S, Park J, Tsung C, Yamada Y, Yang P, Somorjai G (2009) Nature Mater 8:126

24. Nijmeijer A (1999) PhD thesis, University of Twente

25. Stöber W, Fink A, Bohn E (1968) J Colloid Interface Sci 26:62

26. Amiens C, Decaro D, Chaudret B, Bradley JS, Mazel R, Roucau C (1993) J Am Chem Soc 115:11638

27. Schmid G, Maihack V, Lantermann F, Peschel S (1996) J Chem Soc Dalton Trans 589

28. Teranishi T, Hosoe M, Tanaka T, Miyake M (1999) J Phys Chem B 103:3818

29. Sun YG, Xia YN (2002) Science $298: 2176$

30. Graf C, Vossen DLJ, Imhof A, van Blaaderen A (2003) Langmuir 19:6693

31. Marzan LL, Philipse AP (1994) Colloid Surf A 90:95 